\title{
Effects of Explicit Timing on the Reading Fluency of Third Graders with Learning Challenges
}

\author{
Matthias Grünke ${ }^{1}$, Jennifer Karnes ${ }^{1}$, Susanne Hisgen ${ }^{1}$ \\ ${ }^{1}$ Department of Special Education \& Rehabilitation, University of Cologne, Germany \\ Correspondence: Matthias Grünke, Department of Special Education \& Rehabilitation, University of Cologne, \\ Klosterstr. 79b, 50931 Cologne, Germany.
}

Correspondence:

Received: February 1, 2019

Accepted: May 13, 2019 Online Published: May 19, 2019

doi:10.11114/jets.v7i7.4014

URL: https://doi.org/10.11114/jets.v7i7.4014

\begin{abstract}
In this study, we examined the impact of a simple explicit-timing intervention on low-achieving third-grade students' ability to read more rapidly and accurately. We implemented an ABAB design with four struggling readers to establish experimental control and to evaluate the effects of the treatment in terms of the target variable. The results indicated that explicit timing was very helpful in increasing the participants' reading rates. That is, each of the four students demonstrated better mean results in the B phases than in the A phases. The article closes with a discussion of the practical implications and applications of the findings, including limitations to be addressed in future studies.
\end{abstract}

Keywords: reading fluency, explicit timing, single-case study, ABAB design

\section{Introduction}

Reading is crucial for success in school, vocational training, and professional life (Aaron, Joshi, \& Quatroche, 2008). Students who do not master basic reading-related skills by the end of their elementary education have a lower chance of performing effectively in today's society (Wegner, 2017). Unfortunately, many children struggle greatly with the cognitive processes that are involved in decoding letter symbols to determine meaning and, therefore, being able to read fluently. According to Stanat, Schipolowski, Rojsk, Weirich, and Haag (2017), 12.5\% of all fourth-grade students in Germany (where this experiment took place) fall below the minimum standard for reading. If reading problems are not remedied during elementary education, they usually remain until adulthood (Zentall, 2014).

According to Logan's (1988) instance theory of automatization, once students have mastered the letter-sound correspondence rules, they need to learn to read text quickly, accurately, and with little effort so that they can focus on meaning. The ultimate goal of this process is to not only decipher words but also to understand the content of age-appropriate reading materials. However, as a prerequisite for determining the meaning of a text, students must demonstrate adequate fluency (Vellutino, Tunmer, Jaccard, \& Chen, 2007).

Due to the growing challenges presented by increasingly diverse classrooms, many teachers feel overextended by the responsibility of ensuring that no child falls behind in terms of phonological competency or language-processing speed. Thus, there is a great need for interventions that are effective and easy to implement as part of a daily routine. Explicit timing seems to be one such approach. This simple method involves telling students that their academic performance will be timed and providing them with opportunities to check the time remaining before the end of a given assignment. Explicit timing has been found to help boost achievement, at least for learners who demonstrate ample accuracy in a particular skill. If they do not meet this prerequisite, they will not benefit from the intervention (Cates \& Rhymer, 2006; Rhymer, Skinner, Jaskson, McNeill, Smith, \& Jackson, 2002).

The explicit-timing technique typically consists not only of making students aware of the time remaining but also providing them with feedback; for example, in the form of verbal descriptions of scores or diagrams that illustrate progress (Van Houten, Morrison, Jarvis, \& McDonald, 1974). The strategy usually motivates learners to try harder for a given time. It does not have the potential to elicit permanent improvements. As soon as it is no longer applied, performance typically drops (Rathovan, 1999). This does not make explicit timing useless, however. Providing settings in which struggling students accomplish relatively much and experience success is important. It is not only helpful for 
teachers to know what they need to do in order to get their class engaged in an academic task; it is also extremely valuable for children to experience situations in which their effort results in better outcomes (Shengli, 1996).

In recent studies, Dawes (2018), Duhon, House, Hastings, Poncy, and Solomon (2015), and Grays, Rhymer, and Swartzmiller (2017) have demonstrated the benefits of explicit timing in math. In addition, Grünke (2019), Grünke, Knaak, and Hisgen (2018), as well as Grünke, Sperling, and Burke (2017) have documented the positive effects of this intervention on the writing skills (as measured by the length and quality of written texts) of struggling learners of various age groups. However, with one exception, researchers have not tested this technique in other curriculum areas, such as reading. That is, a search of relevant databases (Academic Search Complete, ERIC, Google Scholar, PsycINFO, Scopus, and TOC Premier) for a combination of the terms explicit timing and reading in article titles yielded only one result. In this single-case study, Cates and Rhymer (2006) found that the explicit-timing approach significantly improved four elementary-level students' reading of sight words and phrases.

The aim of the current experiment was to extend and replicate the findings of Cates and Rhymer (2006) by evaluating the usefulness of explicit timing in terms of the reading performance of struggling elementary-level children.

\section{Method}

\subsection{Participants and Setting}

The participants all attended the same third-grade class at an inclusive elementary school in a midsize town in Northrhine-Westfalia (Germany). About $75 \%$ of the students at the school came from an immigrant background, and most spoke German as a second language. To be eligible for the study, the children had to score in the bottom decimal of Stumbling Words: A Reading Test for Elementary Schools (Metze, 2002), a standardized reading inventory. In addition, students had to be able to read with ample accuracy despite their slow pace. Four children met these criteria. Once they were selected, we applied the Number Combination Test (Oswald, 2016) - a nonverbal inventory that is meant to capture fluid intelligence - to assess participants' general cognitive ability.

To protect the four participants' identities, we use the following pseudonyms: Abdi, Ben, Cariba, and David. Abdi, the son of Turkish immigrants who spoke Turkish at home, was 9 years old at the time of the study. According to the Number Combination Test, Abdi's IQ was below average (71.5). Ben, who was 8 years old when the experiment was conducted, is the son of parents with no immigrant background. His IQ was also below average (83.5). Cariba is the daughter of Macedonian parents; she immigrated to Germany with her family when she was 4 years old, and at the time of the study, she was 8. The language spoken in Cariba's home was Macedonian. She had an average IQ (95.5). The final participant, 8-year-old David, is - like Ben - the son of parents with no immigrant background. David had the lowest IQ (70.0) of the four students in the study. Although all four children demonstrated very poor reading skills, with three scoring below the benchmark for average intelligence, none had previously been officially diagnosed with a special need. However, a lack of diagnosis is not necessarily a sign of the absence of disability; rather, it could be an indication that the school sought to avoid labeling.

\subsection{Design and Measures}

We applied a multiple baseline $\mathrm{ABAB}$ reversal design to demonstrate the effects of the intervention. This approach involves an initial baseline phase (A1), followed by an initial introduction of an intervention (B1). The treatment is then removed and baseline conditions are restored (A2), followed by a re-introduction of the intervention phase (B2) (see Ledford \& Gast, 2018). According to Gast and Hammond (2010), the ABAB design "continues to be the simplest, most straightforward evaluation paradigm for evaluating causality with behaviors that are reversible" (p. 248). It is suitable for single-case studies in which a target behavior is under the control of environmental contingencies (Bergan, 2007). The experiment lasted for four school weeks, for a total of 20 daily probes, including five-day periods of each baseline and intervention (explicit timing) condition.

We measured reading performance by counting the number of words from a text passage that a student was able to correctly decode within $1 \mathrm{~min}$. The texts, which we wrote for this research, were 120-word short stories with LIX scores between 35 and 40. The LIX is a common readability index that considers, among other parameters, the proportion of long words and the mean sentence length. The result is a measure of a passage's difficulty. LIX scores can be easily calculated online (http://www.psychometrica.de/lix.html). Indices between 35 and 40 are considered an indication of a very easy-to-read text that is suitable for first- and second-grade students.

\subsection{Procedures}

During the first period of each day of the experiment, a female teaching assistant brought the participants (one at a time) to a resource room in the school. She then sat down with them, handed them a printed story, and asked them to read it out loud as quickly and accurately as possible in response to a starting signal ("Ready? Go!"). When the children made mistakes, the teaching assistant corrected the errors and asked them to reread the section in question. At the end of the 
session, the students were escorted back to their classroom. The order in which the participants went to the resource room for these brief reading exercises varied daily, and no student received the same text more than once.

During the two A phases, where no intervention was implemented, the teaching assistant kept time covertly using a wristwatch. After exactly $1 \mathrm{~min}$ had elapsed, she ended the reading by saying: "Thank you. That will do for today." During the B phases, intervention started by implementing explicit timing. The teaching assistant presented the students with a 12 -inch timer, which she set to exactly $1 \mathrm{~min}$ and placed in front of them on the table. Contrary to the covertly kept time in the baselines, students were constantly able to keep track of the time by looking at the timer out of the corner of their eyes even though they were engaged in reading. Immediately after the exercise, the teaching assistant determined the number of words that the students had correctly read and recorded the data in a line graph. This was easy to do because, in each story, the cumulative number of words was printed next to each line. The last part during the B phases included verbal feedback through an internal attribution (e.g., "I noticed that you tried really hard today, and it paid off - you beat your own record."). If a child did not demonstrate any improvements or did not eagerly engage in the task, feedback contained a variable attribution (e.g., "You did not score as high as yesterday, but still did pretty well. Let's give it another try tomorrow," or "You did not work quite as hard as usual. Next time will be better.") (Chinn, 2010). After each trial, the teaching assistant showed the diagrams to the participants, made them aware of how they had done, and ended the intervention - just as in the A phase - by thanking them for trying hard.

\subsection{Social Validity}

Social validity refers to the significance of the goals, the appropriateness of the procedures, and the importance of the effects (Wolf, 1978). In this study, the teaching assistant captured this element by asking the participants to fill out a short questionnaire at the end of the experiment containing the following statements: (a) "I enjoyed the reading exercises with the timer," (b) "I believe that the timer helped me to read faster," and (c) "I felt motivated to try my best because of the timer." Our participants expressed their views using a 6-point Likert scale from 1 (I absolutely agree) to 6 (I absolutely disagree). The questionnaire was kept simple with no special provisions for ensuring the sincerity of students' responses.

\section{Results}

Figure 1 illustrates the number of words read in 1 min for each of the four participants during each of the 20 trials. We produced this graph, and performed the statistical analyses using the SCAN package for R (Wilbert, 2018). As noted, the students' performance was generally better during the two B phases than during the two A phases. However, the variability in the data was quite large. Overall, the four students did not demonstrate notable improvements within any particular phase. In addition, visual inspection does not suggest a slope effect over time. Instead, performance increased when the explicit timing condition was introduced in Phases B1 and B2, but decreased when the condition changed back to covert timing. 

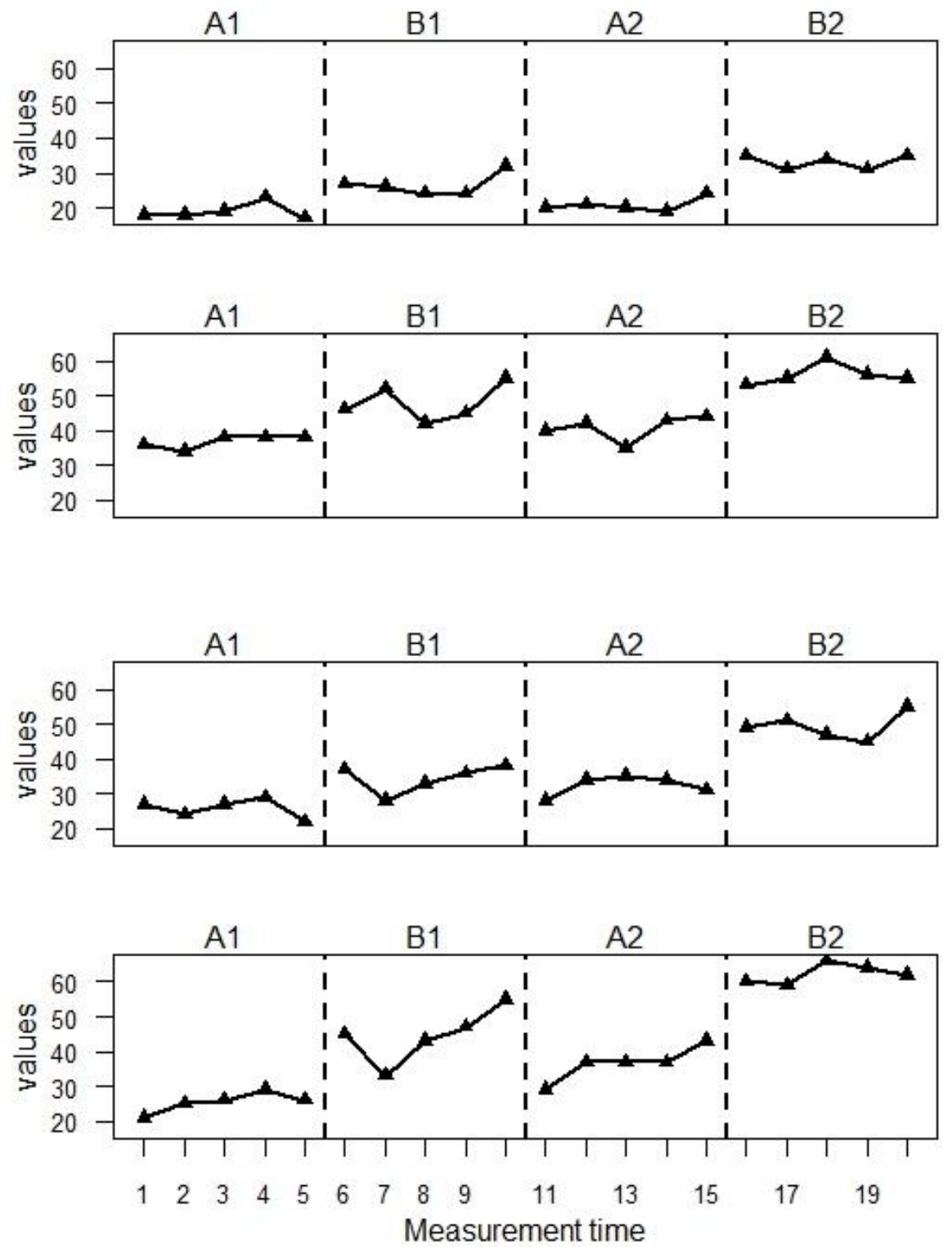

Figure 1. Number of words read correctly in 1 min by Abdi, Ben, Cariba, and David

Figure 2 gives an overview of each participant's mean scores in the four phases. Again, as illustrated, all students performed better under explicit than under covert timing. 


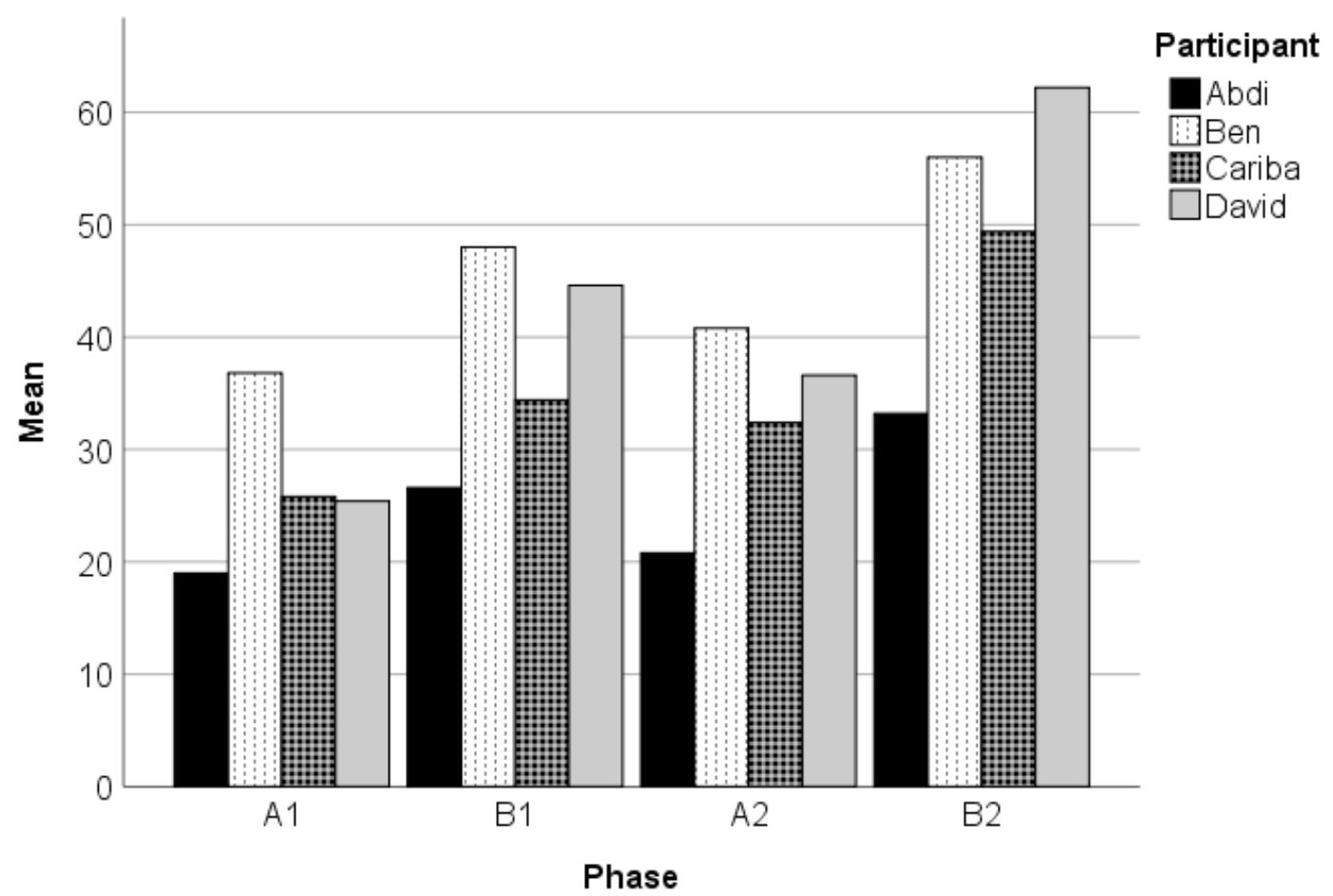

Figure 2. Average number of words read correctly in $1 \mathrm{~min}$

Table 1 presents the results for some of the most commonly used effect-size measures in single-case studies (comparing the A phases with the respective $\mathrm{B}$ phases): percentage of non-overlapping data (PND), percentage of all non-overlapping data (PAND), percentage of data exceeding the median (PEM) and the median trend (PEM-T), and non-overlap of all pairs (NAP) (Lenz, 2013; Parker \& Hagan-Burke, 2007; Parker, Vannest, \& Davis, 2011). PND is the percentage of data from both B phases that exceeds the highest point in the A phases. Unlike PND, PAND uses all available data from all phases. It is defined as $100 \%$ minus the minimum percentage of measurements that would need to be swapped, so that the lowest data point in one of the A phases exceeds the highest data point in one of the B phases. PEM involves calculating the median for the A phases and then identifying the proportion of data points in the B phases that exceed this value. When using PEM-T, a trend line in the first A phase using split-middle technique is drawn and extended to the two treatment phases. The data points in the B phases above the trend line are counted, and the percentage of non-overlap is calculated. Lastly, NAP is defined as the extent to which each data point in the A phases overlaps with each data point in the B phases (Alresheed, Hott, \& Bano, 2013).

Table 1. Effect Sizes for Number of Words Read Correctly in 1 Min

\begin{tabular}{cccccc}
\hline & PND & PAND & PEM & PEM-T & NAP \\
\hline Abdi & 80.00 & 92.50 & 100.00 & 100.00 & 99.00 \\
Ben & 90.00 & 90.00 & 100.00 & 100.00 & 97.50 \\
Cariba & 80.00 & 75.00 & 90.00 & 90.00 & 91.50 \\
David & 80.00 & 90.00 & 100.00 & 100.00 & 95.50 \\
\hline
\end{tabular}

Note. PND = percentage of non-overlapping data; PAND = percentage of all non-overlapping data; PEM = percentage of date exceeding the median; PEM-T = percentage of data exceeding the median and the median trend; NAP = non-overlap of all pairs.

The scores for these indices ranged from respectable to very high. To complete the analysis, we also calculated inferential statistics using piecewise regression modeling (see Van den Noortgate \& Onghena, 2008). When each participant was considered individually (Level 1 analysis; see Table 2), no significant differences in slope occurred between phases. However, for three of the four participants, the level discrepancies between phases B1 and A2 and between phases $\mathrm{A} 2$ and $\mathrm{B} 2$ could not be attributed to chance $(p<.05)$. Cariba was the only exception, as the level difference between phases B1 and A2 for her was not statistically significant. 
Table 2. Piecewise Regression for Number of Words Read Correctly in 1 Min (Level 1 Analysis)

\begin{tabular}{|c|c|c|c|c|c|}
\hline & $\beta$ & $S E$ & $t$ & $p$ & $R^{2}$ \\
\hline \multicolumn{6}{|l|}{ Abdi } \\
\hline Intercept & 18.10 & 2.81 & 6.45 & $<.001 * * *$ & \\
\hline Trend & 0.30 & 0.85 & 0.36 & .73 & .00 \\
\hline \multicolumn{6}{|c|}{ Level by phase } \\
\hline B1 & 4.60 & 3.49 & 1.32 & .21 & .02 \\
\hline A2 & -9.20 & 3.49 & -2.64 & $<.05^{*}$ & .07 \\
\hline B2 & 11.20 & 3.49 & 3.21 & $<.01 * *$ & .10 \\
\hline \multicolumn{6}{|c|}{ Slope by phase } \\
\hline B1 & 0.50 & 1.20 & 0.42 & .68 & .00 \\
\hline $\mathrm{A} 2$ & -0.20 & 1.20 & -0.17 & .87 & .00 \\
\hline B2 & -0.60 & 1.20 & -0.50 & .63 & .00 \\
\hline \multicolumn{6}{|l|}{ Ben } \\
\hline Intercept & 34.40 & 4.11 & 0.37 & $<.001 * * *$ & \\
\hline Trend & 0.80 & 1.24 & 0.65 & .53 & .01 \\
\hline \multicolumn{6}{|c|}{ Level by phase } \\
\hline B1 & 6.30 & 5.11 & 1.23 & .24 & .02 \\
\hline A2 & -12.10 & 5.11 & -2.37 & $<.05^{*}$ & .07 \\
\hline B2 & 11.90 & 5.11 & 2.33 & $<.05^{*}$ & .06 \\
\hline \multicolumn{6}{|c|}{ Slope by phase } \\
\hline B1 & 0.30 & 1.75 & 0.17 & .87 & .00 \\
\hline $\mathrm{A} 2$ & -0.20 & 1.75 & -0.11 & .91 & .00 \\
\hline $\mathrm{B} 2$ & -0.40 & 1.75 & -0.23 & .82 & .00 \\
\hline \multicolumn{6}{|l|}{ Cariba } \\
\hline Intercept & 27.30 & 3.93 & 6.94 & $<.001 * * *$ & \\
\hline Trend & -0.50 & 1.19 & -0.42 & .69 & .00 \\
\hline \multicolumn{6}{|c|}{ Level by phase } \\
\hline B1 & 6.60 & 4.89 & 1.35 & .20 & .02 \\
\hline A2 & -5.80 & 4.89 & -1.19 & .26 & .01 \\
\hline B2 & 14.00 & 4.89 & 2.86 & $<.01 * *$ & .07 \\
\hline \multicolumn{6}{|c|}{ Slope by phase } \\
\hline $\mathrm{B} 1$ & 1.50 & 1.68 & 0.90 & .39 & .01 \\
\hline A2 & -0.40 & 1.68 & -0.24 & .82 & .00 \\
\hline B2 & 0.00 & 1.68 & 0.00 & 1.00 & .00 \\
\hline \multicolumn{6}{|l|}{ David } \\
\hline Intercept & 21.20 & 4.23 & 5.02 & $<.001 * * *$ & \\
\hline Trend & 1.40 & 1.27 & 1.10 & .29 & .00 \\
\hline \multicolumn{6}{|c|}{ Level by phase } \\
\hline $\mathrm{B} 1$ & 6.20 & 5.25 & 1.18 & .26 & .01 \\
\hline $\mathrm{A} 2$ & -23.20 & 5.25 & -4.42 & $<.001 * * *$ & .08 \\
\hline B2 & 17.30 & 5.25 & 3.29 & $<.001 * * *$ & .04 \\
\hline \multicolumn{6}{|c|}{ Slope by phase } \\
\hline $\mathrm{B} 1$ & 2.00 & 1.80 & 1.11 & .30 & .01 \\
\hline $\mathrm{A} 2$ & -0.60 & 1.80 & -0.33 & .75 & .00 \\
\hline B2 & -1.90 & 1.80 & -1.06 & .31 & .00 \\
\hline
\end{tabular}

* Significant on the 0.05 level; ** significant on the 0.01 level; *** significant on the 0.001 level. 
Finally, we aggregated the four single cases into one as part of a Level 2 analysis. The results are shown in Table 3.

Table 3. Overall Piecewise Regression for Number of Words Read Correctly in 1 Min (Level 2 Analysis)

\begin{tabular}{cccccc}
\hline & $\beta$ & $S E$ & $d f$ & $t$ & $p$ \\
\hline Intercept & 34.40 & 9.40 & 88 & 3.66 & $<.001^{* * *}$ \\
Trend & 0.28 & 0.62 & 88 & 0.45 & .65 \\
Level by phase & & & & & \\
B1 & 7.72 & 2.56 & 88 & 3.01 & $<.001^{* * *}$ \\
A2 & -11.36 & 2.56 & 88 & -4.43 & $<.001^{* * *}$ \\
B2 & 13.68 & 2.56 & 88 & 5.34 & $<.001^{* * *}$ \\
Slope by phase & & & & & .19 \\
B1 & 1.16 & 0.88 & 88 & 1.32 & .62 \\
A2 & -0.44 & 0.88 & 88 & -0.50 & .53 \\
B2 & -0.56 & 0.88 & 88 & -0.64 & \\
\hline
\end{tabular}

*** Significant on the 0.001 level.

In the Level 2 analysis, all the level effects were highly statistically significant $(p<.001)$. Thus, explicit timing helped to boost the reading fluency of the participating students. (To learn more about the purpose, the procedures, and the relevance of the Level 1 and Level 2 analyses of data from single-case research, the reader is referred to Manolov and Moeyaert [2017].)

The results of the social validity questionnaire were also very favorable. For the first statement ("I enjoyed the reading exercises with the timer"), the mean score was $1.25(S D=0.50)$; for the second statement ("I believe that the timer helped me to read faster"), it was $2.00(S D=0.00)$; and for the last statement ("I felt motivated to try my best because of the timer"), it was $1.67(S D=0.58)$. Bearing in mind that 1 is the most positive response and that 6 is the most negative reaction, the average indices of between 1.25 and 2.00 were quite good.

\section{Discussion}

This investigation adds to the body of literature on the benefits of explicit timing, a simple intervention that can enhance academic performance. We specifically targeted reading fluency of four struggling third-grade students as a means of laying a foundation for the development of stable text-comprehension skills. The findings indicate that all four participants read considerably more words per minute when they were explicitly timed than when they were covertly timed. A visual inspection of the data suggests that an immediate improvement in performance occurred when the explicit-timing condition was implemented. David, who had with the lowest IQ, seemed to benefit the most in reading performance, because he had more potential for improvement (Ritchie, Bates, \& Deary, 2015). Almost all common non-overlapping effect size indices can be considered as large (see Table 1). According to the piecewise regression analyses for the individual participants, some of the phase comparisons did not yield significant level effects, but most of the contrasts were larger than would be expected due to chance. Moreover, when the four cases were aggregated, the level differences for each pair of phases were highly significant. This is consistent with the findings of Cates and Rhymer (2006).

Despite these promising results, this research is subject to limitations. First, it included only four participants from the same age group and the same school, so the findings cannot be generalized to other populations without serious reservations. Additional studies are needed to confirm that explicit timing improves reading fluency for various groups of students. A second limitation pertains the variability of the data within each phase. Clearly, the use of explicit timing was not the only variable that affected the children's performance. For instance, the way that a participant felt on a particular day could have influenced the number of words that she or he read. Even though we tried to ensure that difficulty levels of the passages were the same, there is no guarantee that each assignment was equally challenging for the students. A third limitation has to do with the brevity of the intervention (4 weeks). That is, if the explicit-timing condition had continued beyond the two 5-day periods, habituation might have set in. Thus, it is difficult to estimate whether the effects of the treatment wear off after routine application. Finally, because we included immediate feedback in the intervention, it is not possible to determine the extent to which this feature vs. explicit timing was responsible for the outcomes. However, because the cumulative number of words was printed next to each line of the texts, and because the participants seemed to constantly pay attention to their scores, the line diagram for feedback probably did not make 
a critical difference.

Despite its shortcomings, this single-case analysis certainly has merits. Operative interventions that are this easy to implement are rare. There is potentially much to gain from explicit timing, and nothing to lose. Thus, this technique is worth exploring in everyday use within a school context. Even if the impact of explicit timing on student performance is not always as great as it was for the participants in this study, the intervention should not be disregarded, as the costs and effort involved are negligible. A high-quality timer such as the one used in this study usually costs a little over $\$ 30$, but a self-made alternative such as a budget-priced wall clock or a timer app projected on a screen can serve the same purpose.

Several recommendations for future research are warranted, including the following: (a) extending the study to include learners of various ages and skill levels, as well as a broad range of curricula and skill areas; (b) examining the effects of long-term explicit timing, and (c) exploring the theoretical foundations of explicit timing.

In summary, explicit timing is a pragmatic approach with a potentially wide range of use. To date, researchers have neglected to explain why this technique is effective at inducing students to try harder and to produce better results. Typically, authors only define explicit timing and point out its potential benefits. There is a need for more research on the theoretical foundations of explicit timing and on the dynamics that come into play when this approach is implemented.

\section{References}

Aaron, P. G., Joshi, R. M., \& Quatroche, D. (2008). Becoming a professional reading teacher. Baltimore, MD: Brookes.

Alresheed, F., Hott, B. L., \& Bano, C. (2013). Single subject research: A synthesis of analytic methods. Journal of Special Education Apprenticeship, 2, 1-18.

Bergan, J. R. (2007). ABAB design. In C. R. Reynolds \& E. Flecthcer-Janzen (Eds.), Encyclopedia of special education, Volume 1 (pp. 7-8). Hoboken, NJ: Wiley.

Cates, G. L., \& Rhymer, K. N. (2006). Effects of explicit timing on elementary students' oral reading rates of word phrases. Reading Improvement, 43, 148-156.

Chinn, S. J. (2010). Addressing the unproductive classroom behaviors of students with special needs. London, UK: Kingsley.

Dawes, J. M. (2018). A comparison of interspersal ratios within an explicit timing intervention to increase multiplication fact fluency (Unpublished doctoral dissertation). Oklahoma State University, Stillwater, OK.

Duhon, G. J., House, S., Hastings, K., Poncy, B., \& Solomon, B. (2015). Adding immediate feedback to explicit timing: An option for enhancing treatment intensity to improve mathematics fluency. Journal of Behavioral Education, 24, 74-87. https://doi.org/10.1007/s10864-014-9203-y

Gast, D. L., \& Hammond, D. (2010). Withdrawal and reversal designs. In D. L. Gast (Ed.), Single subject research methodology in behavioral sciences (pp. 234-275). New York, NY: Routledge. https://doi.org/10.4324/9780203877937-10

Grays, S. D., Rhymer, K. N., \& Swartzmiller, M. D. (2017). Moderating effects of mathematics anxiety on the effectiveness of explicit timing. Journal of Behavioral Education, 26, 188-200. https://doi.org/10.1007/s10864-016-9251-6

Grünke, M. (2019). The effects of a motivational intervention on increasing the writing productivity of students with learning disabilities. International Education Studies, 12, 36-44. https://doi.org/10.5539/ies.v12n3p36

Grünke, M., Knaak, T., \& Hisgen, S. (2018). The effects of a class-wide multicomponent motivational intervention on the writing performance of academically challenged elementary school students. Insights into Learning Disabilities, $15,85-100$.

Grünke, M., Sperling, M., \& Burke, M. D. (2017). The impact of explicit timing, immediate feedback, and positive reinforcement on the writing outcomes of academically and behaviorally struggling fifth-grade students. Insights into Learning Disabilities, 14, 135-153.

Ledford, J. R., \& Gast, D. L. (2018). Single case research methodology: Applications in special education and behavioral sciences. New York, NY: Routledge. https://doi.org/10.4324/9781315150666

Lenz, A. S. (2013). Calculating effect size in single-case research: A comparison of non-overlap methods. Measurement and Evaluation in Counseling and Development, 46, 64-73. https://doi.org/10.1177/0748175612456401

Logan, G. D. (1988). Toward an instance theory of automatization. Psychological Review, 95, 492-527. 
https://doi.org/10.1037/0033-295X.95.4.492

Manolov, R., \& Moeyaert, M. (2017). Recommendations for choosing single-case data analytical techniques. Behavior Therapy, 48, 97-114. https://doi.org/10.1016/j.beth.2016.04.008

Metze, W. (2002). Stumbling words: A reading test for elementary schools. Retrieved from http://www.wilfriedmetze.de/html/stolper.html.

Oswald, W. D. (2016). Number combination test. Göttingen, Germany: Hogrefe.

Parker, R. I., \& Hagan-Burke, S. (2007). Median-based overlap analysis for single case data: A second study. Behavior Modification, 31, 919-936. https://doi.org/10.1177/0145445507303452

Parker, R. I., Vannest, K. J., \& Davis, J. L. (2011). Effect size in single-case research: A review of nine non-overlap techniques. Behavior Modification, 35, 303-322. https://doi.org/10.1177/0145445511399147

Rathovan, N. (1999). Effective school interventions. New York, NY: Guilford.

Rhymer, K. N., Skinner, C. H., Jaskson, S., McNeill, S., Smith, T., \& Jackson, B. (2002). The 1-minute explicit timing intervention: The influence of mathematics problem difficulty. Journal of Instructional Psychology, 29, 305-311.

Ritchie, S. J., Bates, T. C., \& Deary, I. J. (2015). Is education associated with improvements in general cognitive ability, or in specific skills? Developmental Psychology, 51, 573-582. https://doi.org/10.1037/a0038981

Shengli, H. (1996). Academic achievement attribution and reattribution training of schoolchildren in different classroom settings. Acta Psychologica, 28, 268-276.

Stanat, P., Schipolowski, S., Rojsk, C., Weirich, S., \& Haag, N. (2017). IQB-educational trend 2016. Münster, Germany: Waxmann.

Van den Noortgate, W., \& Onghena, P. (2008). A multilevel meta-analysis of single-subject experimental design studies. Evidence-Based Communication Assessment and Intervention, 2, 142-151. https://doi.org/10.1080/17489530802505362

Van Houten, R., Morrison, E., Jarvis, R., \& McDonald, M. (1974). The effects of explicit timing and feedback on compositional response rate in elementary school children. Journal of Applied Behavior Analysis, 7, 547-555. https://doi.org/10.1901/jaba.1974.7-547

Vellutino, F. R., Tunmer, W. E., Jaccard, J., \& Chen, S. (2007). Components of reading ability: Multivariate evidence for a convergent skills model of reading development. Scientific Studies of Reading, 11, 3-32. https://doi.org/10.1080/10888430709336632

Wegner, L. M. (2017). Struggling in school: Language and reading difficulties. In C. A. Galanter \& P. S. Jensen (Eds.), Casebook and treatment guide for child mental health (pp. 199-203). Arlington, MA: American Psychiatric Association.

Wilbert, J. (2018). Package "SCAN": Single-case data analyses for single and multiple AB designs. Retrieved from https://www.uni-potsdam.de/fileadmin01/projects/inklusion/scan/scan.pdf.

Wolf, M. W. (1978). Social validity: The case for subjective measurement or how applied behavior analysis is finding its heart. Journal of Applied Behavior Analysis, 11, 203-214. https://doi.org/ 10.1901/jaba.1978.11-203

Zentall, S. S. (2014). Students with mild exceptionalities: Characteristics and applications. London, UK: Sage. https://doi.org/10.4135/9781506374604

\section{Copyrights}

Copyright for this article is retained by the author(s), with first publication rights granted to the journal.

This is an open-access article distributed under the terms and conditions of the Creative Commons Attribution license which permits unrestricted use, distribution, and reproduction in any medium, provided the original work is properly cited. 